\title{
ÉTICA EMPRESARIAL E SUSTENTABILIDADE EM MOMENTOS DE CRISE: UMA ANÁLISE SOB A PERSPECTIVA DO PRINCÍPIO DA SOLIDARIEDADE
}

\author{
BUSINESS ETHICS AND SUSTAINABILITY IN MOMENTS OF CRISIS: AN \\ ANALYSIS FROM THE PERSPECTIVE OF THE PRINCIPLE OF SOLIDARITY
}

Alexandre Magno Augusto Moreira ${ }^{1}$

Resumo: O presente artigo pretende abordar a ética empresarial e a sustentabilidade em tempos de crise, com a proposta de aplicação do princípio da solidariedade como fundamento a sustentabilidade. Utiliza-se o método de pesquisa hipotético dedutivo, revisão bibliográfica, e, como resposta provisória, a aplicação do princípio da solidariedade como fundamento a sustentabilidade em tempos de crise. Abordar-se-á a ética empresarial, a sustentabilidade empresarial e o entrelace entre responsabilidade social e consumismo. Conclui-se, na utilização do princípio da solidariedade em tempos de crise, como fundamento para a sustentabilidade em favor da empresa e da sociedade.

Palavras-chave: Ética; Ética Empresarial; Sustentabilidade Empresarial; Consumismo; Princípio da Solidariedade;

Abstract: This article aims to address business ethics and sustainability in times of crisis, with the proposal to apply the principle of solidarity as a basis for sustainability. We use the hypothetical deductive research method, bibliographic review, and, as a provisional answer, the application of the principle of solidarity as a basis for sustainability in times of crisis. Business ethics, business sustainability and the link between social responsibility and consumerism will be addressed. It concludes, in the use of the principle of solidarity in times of crisis, as a foundation for sustainability in favor of the company and society.

Keywords: Ethic; Business ethics; Corporate sustainability; Consumerism; Principle of Solidarity;

\section{INTRODUÇÃO}

O processo de evolução social tem se mostrado crescente em épocas de contemporaneidade, e, com graves consequências difíceis de se mensurar. A atividade

\footnotetext{
${ }^{1}$ Doutorando em Direito Empresarial e Cidadania pelo Centro Universitário Curitiba - UNICURITIBA. Mestre em Direito Processual Civil e Cidadania pela UNIVERSIDADE PARANAENSE - UNIPAR - Unidade Universitária de Francisco Beltrão - PR. Coordenador e Professor do Curso de Direito da UNIPAR - Unidade Universitária de Francisco Beltrão - PR. Email: alexandremagno@ @rof.unipar.br.
} 
empresarial desmedida, provocada pelos processos de produção em grande massa nas últimas décadas, proporcionalmente, materializa o avanço da escassez de recursos naturais.

Neste sentido, carece de um olhar delicado, sobre os polos de atividade empresarial sustentável, e consumismo, ambos sob um agir ético, para fins de se estabelecer uma regra de contrapesos em prol da sustentabilidade, notadamente em momentos de crise, como os que ora se vivencia.

Pensando nisso, propõe-se através de uma hipótese (resposta provisória), na utilização do princípio da solidariedade como mecanismo equitativo na atividade empresarial, dentro dos ditames da responsabilidade social e consumismo, em especial nos momentos de crise, a fim de equalizar o processo entre produção e circulação de riquezas, consumo e sustentabilidade.

Para tanto, abordar-se-á, sobre um método de pesquisa hipotético-dedutivo, com revisão bibliográfica, a ética, e a consequente ética empresarial através de suas especificidades. Ainda, pretende-se discorrer aspectos peculiares que distinguem o desenvolvimento sustentável em relação ao significado e alcance da sustentabilidade, com breve abordagem sobre as dimensões da sustentabilidade.

Discorre-se ainda, a relação necessária entre sustentabilidade empresarial e responsabilidade social, de maneira a interligá-la com os propósitos do problema apresentado: a sustentabilidade empresarial e o consumismo em tempos de crise como regra de contrapesos necessários a vida social.

Ao término, sem a menor pretensão de esgotamento do tema, como resposta provisória a discussão apresentada, pretende-se abordar como hipótese, a aplicação do princípio da solidariedade, como fundamento equânime entre a atividade empresarial, responsabilidade social, e o consumismo sustentável, como forma de agir cooperado, em favor da sustentabilidade, notadamente em tempos de crise.

\section{ACEPÇÕES SOBRE A ÉTICA}

A princípio, esclarece-se que os termos ética e moral caminham como uma intersecção (SANCHÉZ VÁZQUEZ, 2010, p. 22). Isto porque, no campo da ética, a expressão é analisada como generalidade teórica, base de análise do investigador, ao se reportar ao conceito do que é bom. Ao interpretar o conceito teórico e prático do que é bom, estar-se-á retratando a moral enquanto conceito. Nesta concepção, atuam de forma paralela enquanto significados, mas 


\section{ÉTICA EMPRESARIAL E SUSTENTABILIDADE EM MOMENTOS DE CRISE: UMA ANÁLISE SOB A PERSPECTIVA DO PRINCÍPIO DA SOLIDARIEDADE}

contribuem e se interferem para a justificativa de determinada regra de comportamento (SANCHÉZ VÁZQUEZ, 2010, p. 18-19).

A ética enquanto definição nos dizeres de Sanchéz Vázquez (2010, p. 23) “(...) é a teoria ou ciência do comportamento moral dos homens em sociedade. Ou seja, é a ciência de uma forma específica de comportamento humano".

Portanto, a ética é a ciência que busca o conhecimento do comportamento humano através da moral, acepção objetiva e geral, não sujeito a interpretações e juízo de valor (ciência), ao passo que a moral, por ser um objeto de estudo da ética, pode ser estudada, investigada, e, portanto, interpretada e flexível (SANCHÉZ VÁZQUEZ, 2010, p. 23-24).

Ainda, sob uma visão filosófica, observa-se que a atitude humana visa uma finalidade a si mesmo, de forma que todo o conhecimento e trabalho engendrado visa um bem colimado, e, nos dizeres de Aristóteles (2003, p. 19), “(...) tanto o vulgo como os homens de cultura superior dizem que esse bem supremo é a felicidade e consideram que o bem viver o bem agir equivalem a ser feliz."

Dita prática do bem, aliada a ideia do prazer é contemplada através da felicidade no sentido de viver de forma agradável, cuja felicidade se contempla como a atividade da alma conforme a virtude (ARISTÓTELES, 2003).

No entanto, o bem não pode ser qualificado com significado específico, mas como ideia universal, absoluta e incondicional sempre desejável em si mesmo e nunca no interesse de outra característica, e, nesse raciocínio, a felicidade enquanto bem supremo, é a busca deste fim em si mesmo e de forma incondicional, diferenciando-se da razão, da honra e do prazer, uma vez que estas, não guardam suas finalidades em si mesmo, e, fazem parte do bem supremo felicidade (ARISTÓTELES, 2003, p. 25-26).

Neste contexto, pode parecer que se esteja ampliando conceitos, mas na verdade, buscase justificar que a felicidade como atividade da alma conforme a virtude perfeita (ARISTÓTELES, 1995, p. 49), vem atrelada a ideia da expressão genérica virtude, que, por sua vez, guarda intrínseca relação com a ética. A virtude ${ }^{2}$ a ser interpretada é a virtude humana (Aristóteles, 2003, p. 37), classificada de virtude intelectual (científica) e moral (valores), objeto de análise do presente, a virtude moral (ARISTÓTELES, 2003).

\footnotetext{
${ }^{2}$ A ética correlacionada a ideia de virtude, encontra-se traduzida na etimologia da palavra, quando se divide de forma clássica, na Grécia antiga, em objetiva (modo coletivo de vida), regra de vida executada pela Lei (nomos) e subjetiva (comportamento individual), através da regra de vida proposta pela virtude (aretê) (COMPARATO, 2006, p. 96).
} 
E por falar em virtude, na concepção de virtude humana da alma (ARISTÓTELES, 1995), a classificação anterior (intelectual e moral), pode ser denominada por dianoética (sapiência e inteligência) que se enrijece pelos ensinamentos, e, por sua vez, a ética (liberalidade e temperança), própria do costume e do hábito (ethos) (ARISTÓTELES, 1995, p. 53-54), ou com maior extensão, ao conjunto de normas que regem a conduta humana (DE LUCCA, 2009).

Em complemento, a ética é contextualizada pela ciência do conhecimento, expressão traduzida do grego êthos-ethos ${ }^{3}$, modo de estar no mundo (DE LUCCA, 2009, p. 61) se caracteriza como forma de vida conquistada pelo homem, um standard ou padrão de conduta a ser seguido, e a moral (do latim mos - mores - costumes) definida como um conjunto de normas adquiridas pelo hábito, comportamento adquirido ou modo de ser conquistado pelo homem (SANCHÉZ VÁZQUEZ, 2010, p. 24).

Pelo exposto, sem que se adentre as divergências científicas do conceito de ética enquanto ciência, ou a defesa de seu significado vinculada a filosofia, fato considerado como uma discussão interminável (DE LUCCA, 2009, p. 69), que demandaria novos escritos específicos a respectivo debate, importa definir a contextualização do termo, ao que se espera no presente escrito, qual seja: delimitá-la enquanto regra de comportamento de conduta em favor de um bem supremo, seja, a felicidade, o prazer, o amor, dentro de todas as variantes que requer o significado, porém, praticada de forma agrupada, conforme preceitua a solidariedade, oportunamente analisada e apresentada como proposta.

\subsection{A ÉTICA NA ATIVIDADE EMPRESARIAL}

Contextualizado o significado e sentido da expressão, sem qualquer pretensão de estabelecer o esgotamento, importa discorrer a ética sob o viés da atividade empresarial, justificando a pretensão do problema da pesquisa.

Importante esclarecer inicialmente, o questionamento proposto por De Lucca (2009, p. 334), quando problematiza o tratamento da ética vinculada a atividade empresarial: de que forma estabelecer uma relação entre ética e atividade empresarial, se, historicamente, em

\footnotetext{
${ }^{3}$ As expressões homônimas êthos e ethos são retratadas por Comparato (2006, p. 96), reportando-se a Grécia antiga, a primeira como morada (domicílio de pessoas ou abrigo de animais) a maneira de ser ou os hábitos de alguma pessoa, e a segunda, os usos e costumes vigentes numa sociedade.
} 


\section{ÉTICA EMPRESARIAL E SUSTENTABILIDADE EM MOMENTOS DE CRISE: UMA ANÁLISE SOB A PERSPECTIVA DO PRINCÍPIO DA SOLIDARIEDADE}

Aristóteles, já se falava na atividade mercantil, voltada ao lucro (chrematisike) ${ }^{4}$, classificada como uma atividade parasita?

Tratava-se, portanto, uma via de mão dupla entre ética e atividade empresarial, uma vez que, o lucro era vislumbrado como atividade de cunho exploratório, o que provocava certa confusão entre a filosofia e religião, a exemplo, na passagem épica, em que Jesus Cristo ${ }^{5}$ expulsou os vendilhões do templo (proibição canônica da cobrança de juros), como um ataque de forma indeterminada aos atos de comércio (DE LUCCA, 2009, p. 334).

Neste sentido, dada a evolução histórica destacada, e, provocava-se a implantação de Códigos de Ética nas guildas medievais vinculadas a cada ofício de atividade mercantil, a exemplo, em Adam Smith, na clássica obra a Riqueza das Nações do ano de $1776^{6}$, o qual estabeleceu uma nova forma de pensar, como reconhecimento fiel de um comércio e uma nova modulação da economia, transformando a atividade lucrativa (chrematisike), atividade fundamental para a sociedade moderna da época (SOLOMON, 1991, p. 355).

Perpassando alguns séculos, De Lucca (2009, p. 335) dispõe que uma das tentativas modernas de edificação da ética aos negócios, originaram-se nos Estados Unidos na década de 60, provocado por uma reação ao estado de desconfiança da população acadêmica nas Universidades, frente aos escândalos de corrupção, uso de informações privilegiadas, bem como ao explícito tráfico de influências.

\footnotetext{
4 Neste sentido, a distinção entre a atividade empresarial econômica (oikonomikos) e a atividade parasita (chrematisike): "Aristotle, who deserves recognition as the first economist (two thousand years before Adam Smith) distinguished two different senses of what we call economics; one of them, oikonomikos or household trading, which he approved of and thought essential to the working of any even modestly complex society, and chrematisike which is trade for profit. Aristotle declared such activity wholly devoid of virtue and called those who engaged in such purely selfish practices 'parasites'. (SOLOMON, 1991, p. 354). Para ilustração, a tradução de Abranches (2004): "Aristóteles, que merece ser reconhecido como o primeiro economista (dois mil anos antes de Adam Smith) distinguia dois sentidos diferentes daquilo a que chamava "economia"; o oikonomikos ou economia doméstica, que ele aprovava e considerava essencial para o funcionamento de qualquer sociedade ainda que pouco complexa, e a chrematisike, a troca que tem como objectivo o lucro".

$5 \mathrm{O}$ processo que provocava a confusão entre filosofia, religião, rendeu dos pensamentos de Aristóteles sobre a prática parasita da atividade visando o lucro até o Século XVII. Em observação, as ponderações de Solomon (1991, p. 355): This, on a large historical canvas, is the history of business ethics - the wholesale attack on business and its practices. Jesus chased the money-changers from the temple, and Christian moralists from Paul to Thomas Aquinas and Martin Luther followed his example, roundly condemning most of what we today honour as 'the business world'. Para ilustrar, a tradução de Abranches (2004): Esta é, a traços largos, a história da ética empresarial - $\mathrm{o}$ ataque indiscriminado ao comércio e às suas práticas. Jesus expulsou os vendilhões do templo, e os moralistas cristãos de S. Paulo a S. Tomás de Aquino e Martinho Lutero seguiram o seu exemplo, condenando rotundamente a maior parte daquilo a que hoje prestamos homenagem como "o mundo dos negócios".

${ }^{6}$ (...) Adam Smith ao publicar a obra a Riqueza das Nações, iluminou todo o mistério sobre o mercado produtivo com apenas um lampejo: "O consumo é o objetivo e o desígnio único de qualquer produção". Atualmente, as questões se dão sobre modelos produtivos e seus aspectos externos, sobre a perspectiva de crescimento e desenvolvimento econômico, a ética corporativa, a produção e o consumo conscientes, sobre a regulação estatal e as falhas de mercado. (DA SILVA, EFING, 2015, p. 89).
} 
A ética empresarial, aos poucos, foi objeto de várias indagações, dentre elas, na constante preocupação, se a sua atividade se constitui ou não, bom negócio para as empresas?

Por uma análise geral, observam-se dois fatores que justifiquem na relação entre ética, atividade empresarial e evolução econômica da empresa. O primeiro, relacionado com a diminuição de custos referente ao controle, uma vez que, empresa comprometida com forte e saudável espírito ético, não dispende de vigilância com produtividade e controle administrativo de seus empregados. O segundo, por sua vez, parte integrante do primeiro, diz respeito ao aumento da produtividade pelo seguinte comparativo: dois trabalhadores, na atividade de quebrar pedras, são indagados do por que estão naquela função? Um deles, responde que está quebrando as malditas pedras, e, o outro, que está em vias da construção de um templo (DE LUCCA, 2009, p. 338-339).

Tal exemplificação que compara a justificativa da atividade dos empregados, nos leva a crer, que o funcionário propenso a cumprir sua atividade pelo simples fato de suprir suas necessidades, é diferente daquele que encontra-se imbuído em um dever moral, que por ele, está a ser cumprido (DE LUCCA, 2009, p. 339). A ilustração não se distancia de qualquer setor que detém a finalidade lucrativa, dita empresarial, um vez que, seja qual for a função exercida, esta deve, acima de tudo, ser executada com probidade e boa-fé, distante de interesses e propensão de crescimento às custas do decréscimo ou demérito de outro colaborador.

A ideia proposta por Solomon (1991, p. 356) ${ }^{7}$, provoca uma evolução do mito do lucro, objetivo proposto por Adam Smith, classificando a atividade empresarial estritamente lucrativa, para convertê-la em lucro e responsabilidade social, de forma que as empresas, além da produção, circulação de bens e serviços com a finalidade de lucro $^{8}$, transforme seus esforços a bem de seus empregados e da sociedade, como uma resposta aos benefícios recebidos em razão da produtividade e lucratividade.

Ademais, concilia-se prática mercantil com a ética, buscando estabelecer níveis de atividade de comércio, quais sejam, o micro nível ou microética, nele consubstanciado pela

\footnotetext{
7 “(...) The new concern is just how profit should be thought of in the larger context of productivity and social responsibility and how corporations as complex communities can best serve both their own employees and the surrounding Society". Neste sentido, a tradução de Abranches (2004): A nova preocupação diz respeito a como deve o lucro ser concebido no contexto mais amplo da produtividade e da responsabilidade social, e como podem as grandes empresas, enquanto comunidades complexas, servir tanto os seus empregados como a sociedade na qual se encontram.

${ }^{8}$ O alcance e sentido da expressão lucro é defendida por Solomon (1991) ao demonstrar que não se trata de um objetivo ou fim da atividade empresarial. O lucro é objeto de compensação e distribuição positiva, pois retribui os empregados, executivos e investidores, trazendo o ganho como satisfação e não como caráter negativo enquanto essência de ganhos.
} 
relação de trocas entre indivíduos (e que guarda a ideia de troca justa, salário justo), e a macroética, em análise mais vastas das questões de Justiça, como uma imagem positiva e global na compreensão dos mundos dos negócios e respectivas funções (SOLOMON, 1991). O terceiro nível, intitulado nível molar, se caracteriza pela análise da empresa, sob a perspectiva da função de dirigentes, empregados, o papel da empresa na sociedade e dos indivíduos na empresa, que somados, todos os níveis englobam a ideia de responsabilidade social ${ }^{9}$.

Como complemento, importa o raciocínio proposto por De Lucca (2009), ao problematizar a ética empresarial, um instrumento do marketing, uma técnica ou fundamento para a rentabilidade da empresa, a ferramenta de propulsão denominada de estelionato moral. Conclui o autor, que deve-se fazer uma análise ao tempo em que vivemos, de forma a se estabelecer limites, em até que ponto a vida ética intervém na atividade econômica.

Neste sentido, não se justifica a ética empresarial, a uma das atividades do ser humano, sem levar em consideração o homem enquanto figura suprema e íntegra. Deve-se, portanto, analisar como premissa, a moral enquanto dimensão universal, para que, a partir dela, se conceba a atividade humana, enquanto atividade ética, vinculada a atividade econômica (DE LUCCA, 2009, p. 341).

Contextualizada a ética, sob uma perspectiva empresarial, importa estabelecer o entrelace entre ética empresarial e sustentabilidade, como forma de justificar a proposta do presente artigo.

\section{CONSIDERAÇÕES SOBRE O DESENVOLVIMENTO SUSTENTÁVEL E SUSTENTABILIDADE}

Inicialmente, as expressões desenvolvimento sustentável e sustentabilidade guardam grande importância, partindo como premissa, da necessária equalização entre desenvolvimento (nele incluído o econômico) de um lado da balança, e, meio ambiente no lado oposto (MAYERLE, 2018, p. 34-35).

\footnotetext{
${ }^{9}$ A responsabilidade social, como ferramenta que justifique os anseios da empresa, na proposta de lucratividade e resposta ética a sociedade e empregados é vislumbrada não pelos stockholders (acionistas), mas os empregados como partes interessadas (stakeholders), aqueles que possuem o direitos, deveres e expectativas com relação a produtividade empresarial, neles concebidos pelos empregados, consumidores, fornecedores, e a sociedade envolvida. (SOLOMON, 1991, p. 357).
} 
O desenvolvimento sustentável ${ }^{10}$, na condição de princípio constitucional $^{11}$ no ordenamento jurídico nacional ${ }^{12}$, historicamente, surgiu na Conferência Mundial de Meio Ambiente realizada no ano de 1972 na cidade de Estocolmo, ante a necessária mudança proveniente do liberalismo, inaplicável diante da revolução de massas (FIORILLO, 2008, p. 27-28). Era preciso de forma urgente, equilibrar o descontrole da utilização de recursos naturais (esgotáveis), e, de forma paralela, permitir a constância da atividade econômica produtiva, no entanto, por intermédio do intervencionismo estatal ${ }^{13}$.

Em raciocínio similar, porém, guardada as respectivas peculiaridades, a sustentabilidade ${ }^{14}$ pode ser vista como a capacidade de percepção de resiliência entre os seres humanos e o meio ambiente, de forma a se determinar simultaneamente, quais são as condições favoráveis a manutenção, adaptação de uma vida (humana e não humana) equilibrada, através de uma matriz que engloba aspectos biológicos, físicos, químicos, políticos, culturais, econômicos, tecnológicos, dentre outros (MAYERLE, 2018, p. 36).

Percebe-se, portanto, que os termos Desenvolvimento Sustentável e Sustentabilidade, em que pese as expressões guardarem certa similitude, e, muitas vezes utilizadas como sinônimos, importante que se entenda, que são expressões distintas, mas que seus sentidos comungam, com vias ao equilíbrio entre atividade humana e preservação de recursos naturais esgotáveis.

Para efeito de se delimitar o objeto da pesquisa, passa-se a analisar as dimensões da sustentabilidade, para então, se adentrar a discussão quanto a sustentabilidade empresarial.

\footnotetext{
${ }^{10}$ No dizeres de Machado (2011, p. 161) "A palavra sustentável é boa porque significa que suficiente é conseguir com que a economia cresça, sem destruir os recursos e o ambiente dos quais o futuro depende, para manter o crescimento econômico de forma que os impactos sociais e ambientais desse crescimento permaneçam em equilíbrio".

${ }^{11}$ O primado do Desenvolvimento Sustentável é positivado no artigo 225 da Constituição Federal, do qual extraise o caput: "Art. 225. Todos têm direito ao meio ambiente ecologicamente equilibrado, bem de uso comum do povo e essencial à sadia qualidade de vida, impondo-se ao Poder Público e à coletividade o dever de defendê-lo e preservá-lo para as presentes e futuras gerações”. (BRASIL, 1988).

${ }^{12}$ A proteção do meio ambiente é um direito preponderante, quando se compara aos direitos fundamentais da propriedade, iniciativa privada, por exemplo, pois equiparado ao direito fundamental à vida, que encontra-se em jogo, quando se está em destaque a qualidade do meio ambiente, para fins de se estabelecer a qualidade da vida humana. (DA SILVA, 2011, p. 851).

13 "Chegou-se, assim, a conclusão de que meio ambiente e desenvolvimento sustentável são temas que podem - e devem - ser harmonizados. (...) A harmonia consiste, justamente, no desenvolvimento sustentável, norte de toda ciência ambiental. (SOUZA, 2007, p. 15).

${ }^{14}$ Apesar da analogia, sustentabilidade e desenvolvimento sustentável caminham de forma integrada para a compreensão na relação entre atividades humanas e meio ambiente. A sustentabilidade abrange os sistemas e o próprio desenvolvimento sustentável no que diz respeito a necessidades humanas e bem-estar. O desenvolvimento sustentável, é a forma de acesso, porta de entrada para se atingir a sustentabilidade. A sustentabilidade consiste em uma meta ou parâmetro (objetivo final), definido por meio de critérios científicos, que mensura e acompanha os resultados gerados pela utilização de estratégias do desenvolvimento sustentável. (FEIL; SCHEREIBER, 2017).
} 


\section{ÉTICA EMPRESARIAL E SUSTENTABILIDADE EM MOMENTOS DE CRISE: UMA ANÁLISE SOB A PERSPECTIVA DO PRINCÍPIO DA SOLIDARIEDADE}

\subsection{AS DIMENSÕES DA SUSTENTABILIDADE}

Em análise aos aportes teóricos acerca da sustentabilidade e suas dimensões, percebe-se inúmeras divisões, no entanto, parte-se da premissa da classificação tradicional tríade, nela intitulada Triple Botton Line (TBL - tripé da sustentabilidade), em seus aspectos econômicos, de natureza social, bem como ecológicos (SOLER et al., 2018, p. 65) ${ }^{15}$.

Sob o viés social, têm-se por fundamento, a análise de dois conceitos bases: as necessidades essenciais da população pobre do mundo, e, a organização social no que diz respeito a capacidade do meio ambiente em atender necessidades do presente e futuro (MAYERLE, 2018, p. 42), nelas inclusas, a atenção aos recursos humanos, saúde e seguridade dos consumidores, o impacto na comunidade (SOLER et al., 2018, p. 65). Melhor dizendo, o equilíbrio em atender a sociedade se perfaz, sem que comprometa as necessidades futuras dos seres humanos.

Pelo aspecto econômico, em síntese, trata-se de produzir, distribuir e utilizar de forma equilibrada e justa as riquezas produzidas pelo homem, a ponto de comparar a sustentabilidade com a viabilidade de se gerar riqueza para a empresa, peculiaridade do capitalismo (empresa economicamente viável no mercado) (MAYERLE, 2018, p. 52).

Na dimensão ambiental, ligada a aspectos relacionados com o uso de recursos hídricos, energéticos, proteção a biodiversidade, habitats naturais e produções limpas (SOLER et al., 2018, p. 65), concebe-se que a vida seja objeto de proteção, na sua relação entre homem e meio ambiente, dada a íntima relação entre ambos, do presente, para as futuras gerações (MAYERLE, 2018, p. 40). Trata-se do “(...) o uso racional dos recursos naturais, o consumo de combustíveis fósseis, de recursos renováveis e não renováveis em geral, reduzir o volume de resíduos e de poluição através da política 3R (reduzir, reutilizar, reciclar)". (FROEHLICH, 2014, p. 157).

Portanto, em que pese as várias classificações das dimensões, ilustra-se a classificação tríade, e, em ato subsequente, se estabeleça o liame com a sustentabilidade na atividade empresarial.

\footnotetext{
15“'O modelo apresentado pelo tripé estabelece que um empresa que busque um desenvolvimento sustentável, deve ser avaliada pelas partes interessadas não somente sobre os valores econômicos de rentabilidade, mas também, pelos benefícios auferidos com a equidade e justiça social, em especial, na proteção com o meio ambiente". (SOLER et al., 2018, p. 65).
} 
2.2 SUSTENTABILIDADE EMPRESARIAL E RESPONSABILIDADE SOCIAL: AS AMARRAS NECESSÁRIAS

Estabelecida de forma conceitual, a ética empresarial e o significado da sustentabilidade sob o ângulo de suas dimensões, entende-se pertinente interligar as expressões ética, sustentabilidade e atividade empresarial, para que, oportunamente, possa se explicitar o problema da pesquisa em análise.

Como visto, falar em ética empresarial, reputa-se necessário fazer menção a sustentabilidade $^{16}$. A justificativa a esta assertiva é lógica, na medida em que a empresa, para a realização da atividade produtiva de produção e circulação de mercadorias, além da finalidade do lucro, deve estar voltada também, a preocupação com a preservação do meio ambiente e os cuidados com a escassez dos recursos naturais, a preocupação com o meio ambiente do trabalho e salubridade de seus empregados ${ }^{17}$.

Além da relação interna, os reflexos da sustentabilidade se disseminam para a relação com terceiros. Ao analisar os limites e alcance do Pacto Global, tratativa de adesão livre por parte de empresas e sociedade civil (TAMIOZZO; KEMPFER, 2016, p. 151), observa-se que uma das preocupações do pacto é a participação das empresas as redes de sustentabilidade, a exemplo, quanto a não violação a direitos humanos. Empresa comprometida, é aquela que não se relaciona com outras empresas que se utilizam de mão-de-obra escrava e exploração infantil, por exemplo (TAMIOZZO; KEMPFER, 2016, p. 155-156).

Portanto, a responsabilidade interna, relacionada com os direitos vinculados a atividade empresarial interna corporis, une-se com as responsabilidades de natureza externa, das quais destacam a preocupação com a sustentabilidade na dimensão social e ambiental, nas operações de produção, circulação de mercadorias e prestação e serviços, na colaboração com a comunidade em que encontra inserida e com o Estado, para se alcançar parâmetros de bemestar coletivo (BARBOSA; SIMÃO FILHO, 2018).

\footnotetext{
${ }^{16}$ A sustentabilidade é vista ainda, como uma ferramenta útil ao restabelecimento de empresas no processo de recuperação judicial. Neste sentido, “(...) uma empresa que tenha se preocupado com a dimensão social da sustentabilidade, mantendo relações saudáveis com seus colaboradores, fornecedores e a sociedade em geral, por certo contará com a boa vontade destes na execução do plano de recuperação. O comprometimento dos empregados, bem como a confiança dos credores influenciará positivamente na consecução do pacto de reestruturação". (LANZARINI; BODNAR, 2020, p. 136).

17 Trata-se dos efeitos da responsabilidade social, na medida em que, a responsabilidade social empresarial encontra-se relacionada de forma intrínseca com o discurso ético, pois a empresa, em suas decisões, ao considerar a ética enquanto valor, manifesta-se sempre preocupada com a qualidade e impacto de suas ações incidente sobre as pessoas, as outras organizações, a economia e o meio ambiente. (TAMIOZZO; KEMPFER, 2016, p. 148-149).
} 
Desta forma, o grande desafio de toda atividade empresarial de natureza sustentável, é estabelecer práticas vinculadas a função social, e, em consequência, atingir a responsabilidade social, atendendo não somente interesses particulares, mas sim, os intentos da coletividade. Assim, cumpre sua função social como primado de toda a conduta externada em busca da responsabilidade social e não como forma de externar um caráter limitador a autonomia privada. (SILVA; SELLOS KNOERR, 2013, p. 445).

O lucro como ultima ratio da atividade empresarial não é o fim na contemporaneidade, mas sim o resultado dela, que deve ser pretendido de acordo com o desenvolvimento sustentável e inclusão social (a nova empresarialidade), externalizando a responsabilidade social da empresa (BARBOSA; SIMÃO FILHO, 2018, p. 276).

Apresentado os aportes teóricos, percebe-se o sentido e alcance das amarras indispensáveis entre atividade empresarial, responsabilidade social e sustentabilidade, pois, quando se fala em sustentabilidade empresarial, se está diante da salubridade de atividades internas da empresa em favor de seus colaboradores e terceiros, e, mais ainda, com reflexos desta atividade a coletividade (ao Estado e sociedade civil), sem que se olvide, aos reflexos externos, nos benefícios ao meio ambiente, na preservação dos recursos naturais esgotáveis.

\section{SUSTENTABILIDADE EMPRESARIAL E CONSUMISMO EM MOMENTOS DE CRISE: A REGRA DE CONTRAPESOS}

Delineada as ideias propostas de sustentabilidade, atividade empresarial, na conduta ética empresarial com foco em sustentabilidade, torna-se importante realçar, a relação entre as condutas empresariais, e, a política de consumo realizada por consumidores no cenário atual de crise.

De acordo com pesquisas publicadas ${ }^{18}$ pela Sociedade Brasileira de Varejo e Consumo SBVC (2020), o aumento de compras on line realizada pelos brasileiros em tempos de pandemia, se demonstra crescente e perdurará inclusive no período pós-crise. Tais reflexos culminaram inclusive, em recente alteração legislativa, no que diz respeito a transitoriedade de

\footnotetext{
${ }^{18} \mathrm{O}$ estudo foi retratado pela Sociedade Brasileira de Varejo e Consumo em parceria com a Toluna (fornecedora líder de insights do consumidor sob demanda), no documento intitulado "Hábitos de consumo adquiridos na pandemia deverão permanecer no pós Covid". O estudo mostra que $61 \%$ dos clientes que compraram durante a quarentena de forma on line, aumentaram o volume de compras on line devido ao isolamento social, e, em $46 \%$ dos casos, este aumento foi superior a 50\%, com destaque no consumo de alimentos e bebidas (delivery) (SBVC, 2020).
} 
regras do direito privado, que impediu, por exemplo, o direito de arrependimento pelo consumidor (art. 49 do Código de Defesa do Consumidor) nas compras de produtos on line até o mês de Outubro de 2020 para produtos perecíveis, de consumo imediato e de medicamentos, com a possibilidade de respectiva prorrogação ${ }^{19}$.

Observa-se atentamente no mercado globalizado, em especial no modelo capitalista em que fixa-se a produção para o consumo (SARRETA, 2015, p. 17), uma oferta uniforme de produtos em massa de forma desnecessária, o que provoca o consumo excessivo ou o hiperconsumo, inócuo pelo simples prazer $^{20}$, sob o ponto de vista da economia, da nocividade entre os sujeitos da relação (empresas - consumidores), e, para o caso em tela, os reflexos perniciosos para a sustentabilidade.

Pode-se dizer, que o liame entre consumo sustentável ético e pandemia, é provocado por uma ruptura, melhor dizendo, na dicotomia entre produção capitalista sustentável, e o equilíbrio com o consumismo, uma vez que, no dizeres de Bauman (2001, p. 9), há que se considerar a presente fase, como fluída ou líquida no atual contexto de relações.

Em complemento, a sociedade historicamente sólida, resistente em demasia para se amoldar a atualidade face ao enrijecimento de caminhos habituais, na realidade atual, se esvai ante a liquidez das transformações, a quebra da moldura, de padrões e modelos de conduta, de forma que, "os poderes que liquefazem passaram do "sistema" para a "sociedade", da "política" para as "políticas da vida" - ou desceram do nível "macro" para o nível "micro" do convívio social (BAUMAN, 2001, p. 15).

Esta regra de contrapesos entre oferta de produtos de forma sustentável, e a relação ou a dicotomia existente entre consumo ${ }^{21}$, provocam grandes incertezas e a manifesta insegurança sobre um contexto da atividade empresarial, no agir ético sustentável, em especial nos momentos de modernidade líquida, e quebra de padronização, frente as adaptações provocadas pelo novo normal.

\footnotetext{
${ }^{19}$ É o que retrata, a disposição do artigo $8^{\circ}$ da Lei 14.010 de 2020: Art. $8^{\circ}$ Até 30 de outubro de 2020, fica suspensa a aplicação do art. 49 do Código de Defesa do Consumidor na hipótese de entrega domiciliar (delivery) de produtos perecíveis ou de consumo imediato e de medicamentos.

${ }^{20}$ O hiperconsumo foi destacado como paradoxo da felicidade pelo filósofo Gilles Lipovetisky na obra "A felicidade paradoxal: ensaio sobre a sociedade do hiperconsumo" ao fazer menção de que as motivações de consumo, na atualidade, encontravam-se baseadas não na diferença social, mas no individualismo e no prazer (hedonismo), alcançando as camadas populares e mais jovens, o consumo baseado no bem-estar e na busca da felicidade individual (AMORIM et. al., 2018, p. 73-74).

${ }^{21}$ Revela-se pertinente os propósitos de Bauman (2001, p. 96), quando demonstra o consumismo pela queda do arquétipo de satisfação de necessidades, para a transformação da necessidade de consumo para o desejo, algo extremante volátil, efêmero, de forma que o objeto do desejo, está constantemente sujeito a impossibilidade de saciedade.
} 
Há, portanto, em suma, a oferta em massa, o consumo excessivo, em descompasso com a ideologia de sustentabilidade, o que provoca em especial nos momentos de crise em que se vivencia, uma dificuldade na regra de contrapesos entre consumo e sustentabilidade na atividade empresarial, sob a perspectiva de um agir ético.

No outro lado da balança, oposto as regras de consumo, têm-se a atividade empresarial, que se requer as exigências de produção, sem levar em consideração exclusiva a finalidade lucrativa. Neste mote, para se exigir do cidadão, o consumo ideal, proporcional, não nocivo e com reflexos sustentáveis, indispensável que a empresa faça o dever de casa.

E quando se fala em dever de casa, importa elucidar o novo paradigma da responsabilidade social empresarial, ao se questionar: o que é que os cidadãos estão exigindo das empresas? (SEN; KLIKSBERG, 2010).

Exige-se políticas internas no sentido de cumprir a tarefa de casa (condições dignas, remuneração justa, capacitação de pessoal); transparência e boa governança corporativa (probidade na conduta dos acionistas e diretores); jogo limpo com o consumidor (produtos de boa qualidade, preços razoáveis e produtos saudáveis); políticas ativas de proteção ao meio ambiente (instituições limpas do ponto de vista ambiental); integração aos grandes temas em prol do bem estar comum (políticas públicas relacionadas a sociedade civil, como deserção escolar e melhoria na qualidade de ensino); e, não praticar um código de ética duplo, de forma a coadunar a política da empresa, interligada aos propósitos e estímulo dos funcionários em favor do agir ético (SEN; KLIKSBERG, 2010, p. 363-364).

Portanto, entre a face da responsabilidade social, e, em oposição a ideia de consumismo desmedido em tempos de crise, em especial no foco acerca da pandemia, observa-se a necessária visão de equilíbrio e respeito mútuo entre os atores do processo de produção, circulação e consumo de produtos, para efeito de se atingir uma suscetibilidade do fiel agir ético, e mais, para prosperar a preocupação direta aos efeitos da sustentabilidade, com vias a se compreender o significado moderno do risco nas atividades econômicas.

Neste norte, o risco a que se refere, é o problema de grandezas estabelecido entre distribuição de riquezas, proporcional a distribuição dos riscos. Quanto maior a produção, maior o consumo e aumento de riquezas, no entanto, maior o risco (BECK, 2010).

Como complemento, os riscos: se sobrepõem a toda e qualquer resultado produtivo avançado, a exemplo, a radioatividade (consequência invisível, muitas vezes irreversível); projetam o efeito bumerangue, vez que, quando do seu retorno não escolhem o alvo (pobres ou 
ricos) seja pelos riscos à saúde dos vulneráveis, seja pela perda de legitimidade e força em Acordos Internacionais frente a poluição provocada; a ação canibal econômica dos riscos, provoca com que as empresas produzam situações de ameaça e o potencial político da sociedade de risco; a política dos riscos deve ser vista como uma consciência prévia, altamente estudada para se evitar a existência ou a consequência (BECK, 2010, p. 27-28).

Os riscos, ao contrário do que se via como forma de antever a futuras catástrofes e consequências negativas ao contexto de uma sociedade e da própria natureza, visualiza, como é o caso da pandemia do COVID-19, efeitos colaterais sob uma análise macro, vista sobre aspectos econômicos, sociais e políticos, das quais destacam-se, a perda de mercado, depreciação do capital, aumento do câmbio, procedimentos judiciais e a perda de prestígio, aliado as catástrofes da natureza, efeitos colaterais negativos sob a política, economia e sociedade (BECK, 2010, p. 28).

É preciso, portanto, na regra de contrapesos entre sustentabilidade empresarial e consumismo em prol da sustentabilidade, antever os riscos, precaver as consequências. A atitude comissiva sem a visão premeditada das consequências oriundas de tais atos, provoca a desproporção na regra de pesos, a ruptura do equilíbrio necessário ao pensamento ético que se deva produzir nos dias atuais.

As transformações sociais diluídas e emergentes, devem estar acompanhadas na exata medida da antecipação dos riscos, seja para o lado da atividade empresarial, seja para o lado do responsável pelo consumo, de forma que, a sustentabilidade possa atingir a possibilidade ou a proximidade de seus propósitos.

Em termos, considerando a regra de contrapesos entre sustentabilidade empresarial e consumismo, passa-se a discorrer acerca da proposta de aplicação do princípio da solidariedade, como justificativa viável a equalizar, atividade empresarial, consumo e sustentabilidade.

\subsection{SUSTENTABILIDADE EMPRESARIAL EM TEMPOS DE CRISE: UM OLHAR SOB A PERSPECTIVA DO PRINCÍPIO DA SOLIDARIEDADE}

Em princípio, é indispensável falar em sustentabilidade no que diz respeito a atividade empresarial, levando em consideração o atual momento já relatado em tópico anterior, qual seja, as extremidades do "cabo de guerra" entre o aumento do consumo em tempos de crise, atividade empresarial com fins lucrativos versus sustentabilidade. 


\section{ÉTICA EMPRESARIAL E SUSTENTABILIDADE EM MOMENTOS DE CRISE: UMA ANÁLISE SOB A PERSPECTIVA DO PRINCÍPIO DA SOLIDARIEDADE}

Para fazer valer a resposta provisória a presente hipótese ${ }^{22}$, utilizar-se-á como fundamento, a aplicação do princípio da solidariedade, como primado para se estabelecer o equilíbrio entre atividade empresarial, consumismo e sustentabilidade, na pretensão, notadamente, da união de esforços em prol de um agir ético coletivo entre os atores deste processo, em especial, no momento de crise vivenciado.

Neste norte, a solidariedade enquanto significado, se traduz pela expressão solidum, na totalidade de uma soma, materializada não como unidade isolada, mas como agrupamento destas unidades (COMPARATO, 2006, p. 577). A ilustração proposta por Comparato (2006) faz da solidariedade na expressão metafórica do "fecho da abóbada" dos sistemas de princípios, como complemento a liberdade, a igualdade e a segurança.

Como contraponto, a liberdade e a igualdade, dispõem as pessoas em relação uma das outras no agir dentro de suas perspectivas individuais, ao passo que que a solidariedade reúne estas pessoas. A solidariedade pretende reunir as pessoas para um fim comum, na união dos grupos que a compõem, caracterizando esta sociedade política, como finalidade última e de forma ética, proporcionar o aperfeiçoamento constante de todos os membros, segundo as particularidades e qualidades de cada membro (COMPARATO, 2006, p. 577-578).

A solidariedade é contextualizada ainda, sob a abrangência de 3 (três) dimensões: nacional $^{23}$, internacional e intergeneracional, e a cada uma delas composta de um corpo normativo. O vínculo estabelecido pela solidariedade se dá em razão dos direitos tutelados em cada uma destas dimensões, em destaque, os primeiros sistemas constitucionais (Constituição Mexicana de 1917 e alemã - aprovada em Weimar de 1919), com a consequente Carta das Nações Unidas nas disposições do art. 55, que prevê o direito ao reconhecimento do desenvolvimento de cada agrupamento (COMPARATO, 2006, p. 580), e, os direitos econômicos, sociais e culturais amparados pela Declaração Universal dos Direitos Humanos

\footnotetext{
${ }^{22}$ A justificativa ao método de pesquisa utilizado no presente artigo, qual seja, o hipotético dedutivo, se traduz no presente ensaio, como forma de se estabelecer uma resposta provisória à pergunta, representada por uma hipótese ao problema apresentado, ao ponto de se estabelecer a resposta através do confronto com o mundo dos fatos materializados (QUIVY; CAMPENHOUDT, 2005, p. 121).

${ }^{23}$ Pelo aspecto nacional, vale destacar a Constituição Federal, quando expressa no artigo $3^{\circ}$ inciso I, um dos objetivos fundamentais da República, a construção de uma sociedade livre, justa e solidária. Quando se idealiza uma sociedade justa, é na importância do alter (outro), e por isto, a alteridade, que se encontra a razão das coisas. A identidade da solidariedade se consolida na vida em comunidade, na posse e gozo, amigos e inimigos, vontades de defesa e proteção, de forma que os homens abriram mão de suas liberdades, para as liberdades consentidas, a adaptação do homem ao seu ambiente natural, de forma que a relação entre homens, para fins de se superar a indiferença, se dá na medida do alcance de chances iguais de dignidade na sociedade (CARDOSO, 2012, p. 1920).
} 
$(\operatorname{artigo} \mathrm{XXII})^{24}$.

Frente ao raciocínio proposto, o diálogo entre os atores no propósito do agir ético entre atividade empresarial e consumo em prol da sustentabilidade, a partir da perspectiva do primado da solidariedade, se faz da necessária construção coletiva de finalidades, no alcance de causa e efeito comum, no fazer em prol da coletividade, com mais altruísmo e menos egoísmo. Os resultados da responsabilidade social empresarial jamais serão alcançados se o agir ético no tocante ao consumismo exacerbado e lucro permanecer.

Trata-se, portanto, da metáfora apresentada pela equação matemática entre atividade empresarial, responsabilidade social e solidária, adicionada ao consumismo ético solidário, o que provocará, como resultado da regra, a sustentabilidade, seja sobre o viés da preservação ambiental, seja pelo aspecto econômico, social, político em todas as suas vertentes.

É preciso que se tenha atitude, e mais, atitude coletivizada, uma vez que, nos dizeres de Sen e Kliksberg (2010, p. 9), ao citar o pensamento de Ghandi "a diferença entre o que fazemos e aquilo que somos capazes de fazer, bastaria para solucionar a maioria dos problemas do mundo".

A solidariedade é uma proposta ou alternativa para a realização conjunta em prol da sustentabilidade, no âmbito da atividade empresarial em busca de uma constante preocupação com a responsabilidade social, levando em consideração a empresa, funcionários e a sociedade, e, por sua vez, o cidadão em suas liberdades no consumismo e o respeito a estes limites, em franca relação conjunta, como uma forma de provocar as amarras entre estas relações.

Os momentos de crise que ora se vivenciam, faz eclodir, a preocupação $\operatorname{com}$ os riscos ${ }^{25}$, e mais, atitudes imediatas, para se minimizar prejuízos que já estão em franca execução. Portanto, o agir ético é iminente, e requer, além da individualidade através da ética, o agir ético coletivo, como prática do primado da solidariedade, pra efeito do alcance ao resultado da sustentabilidade, no plano de equalização entre atividade empresarial, e sociedade de consumo.

\footnotetext{
${ }^{24}$ Artigo XXII. Todo ser humano, como membro da sociedade, tem direito à segurança social, à realização pelo esforço nacional, pela cooperação internacional e de acordo com a organização e recursos de cada Estado, dos direitos econômicos, sociais e culturais indispensáveis à sua dignidade e ao livre desenvolvimento da sua personalidade.

${ }^{25}$ A solidariedade da carência é substituída pela solidariedade do medo na sociedade de risco. Desta forma, o sistema axiológico de uma sociedade de risco (desigual) é a insegurança, e, a utopia de uma sociedade segura não se objetiva em alcançar o que é efetivamente bom, mas sim, de se evitar o pior. A sociedade de classes é expressada pela frase: tenho fome! A sociedade de risco, marcada pela frase: tenho medo! Neste sentido, a solidariedade da carência, é substituída pela solidariedade do medo, que requer urgência e uma força política de contenção (BECK, 2010, p. 59-60).
} 


\section{CONCLUSÃO}

Conclui-se que a ética, enquanto regra de comportamento humano, encontra-se intimamente interligada com a atividade empresarial e práticas de consumo, circunstância que deve estar fomentada ao tempo de crise em que se vive.

O comportamento das empresas em observância a preocupação com a responsabilidade social, não depende de forma exclusiva, de sua realização plena em favor dos atores da atividade empresarial. Mais que benefícios empresariais, a sociedade precisa receber os benefícios e reflexos decorrentes da atividade empresarial.

Por outro lado, para se sustentar a balança, com vias a equalizar o processo sustentável de produção e circulação de riquezas, torna-se indispensável enxergar o cidadão, como consumidor e parte integrante deste processo.

Neste sentido, ao vivenciar uma sociedade que não se preocupa no processo contemporâneo, com conceitos sólidos, modelos ou standards, mas com a fluidez de ações e significados, o risco de consequências nefastas sobre aspectos econômicos, políticos, jurídicos e sociais, torna-se um estopim, com resultados incalculáveis sobre o viés da sustentabilidade.

Portanto, propõe-se a aplicação do princípio da solidariedade como fundamento sustentável capaz de provocar a equalização entre atividade empresarial e consumismo, notadamente, em processos de crise que atualmente se vivencia.

$\mathrm{O}$ agir ético deve ser coordenado, executado de forma concatenada entre os atores sociais da atividade empresarial e do consumo.

Não basta cada agrupamento (empresa ou cidadão) fazer a sua parte. Torna-se relevante, que além das tarefas individuais de cada um dos grupos deste processo, se externalize o comprometimento comum e coordenado, ultrapassando as instâncias das liberdades individuais e dos interesses coletivos, para que a execução das ações seja perpetrada de forma difusa, sem limites de fronteiras ou classes determinadas.

Utilizando-se a proposta de aplicação do princípio da solidariedade, como ferramenta hábil ao processo de integração entre atividade empresarial e consumismo, a união de esforços promoverá resultados satisfatórios em prol da sustentabilidade.

Atividade empresarial sustentável e consumismo sustentável não podem, nem devem se desvincular. Tratam-se de ações, que apesar de muitas vezes organizadas dentro de suas particularidades, restam-se não cooperadas (solidárias), e, sob a perspectiva do princípio da 
solidariedade, devem ser onipresentes, uma ubiquidade no processo de atividade empresarial e consumo em prol da sustentabilidade.

\section{REFERÊNCIAS}

AMORIM, E. S. M. S; SILVA, E. R. S.; ROSA, J.; PEREZ, C. O princípio do prazer: o hiperconsumo como escape em tempos de modernidade líquida. Signos do Consumo, São Paulo, v. 10, n. 2, p. 70-78, jul./dez. 2018.

ARISTÓTELES. Ética a Nicômaco. São Paulo: Editora Martin Claret, 2003.

ARISTÓTELES. A Ética. Tradução de Paulo Cássio M. Fonseca. Bauru, SP: EDIPRO, 1995.

BARBOSA, K. de S; SIMÃO FILHO, A. A nova Empresarialidade: o robustecimento dos valores éticos e sociais no exercício empresarial. Revista de Direito Econômico e Socioambiental, Curitiba, v. 9, n. 1, p. 269-294, jan./abr. 2018. Disponível em: https://periodicos.pucpr.br/index.php/direitoeconomico/article/view/16376. Acesso em: 16. Ago. 2020.

BAUMAN, Z. Modernidade Líquida. Tradução de Plínio Dent-Zien. Rio de Janeiro: Zahar, 2001.

BECK, U. Sociedade de Risco: rumo a uma outra modernidade. Tradução de Sebastião Nascimento. São Paulo: Editora 34, 2011.

BRASIL. Constituição da República Federativa do Brasil de 1988. Disponível em: < http://www.planalto.gov.br/ccivil 03/Constituicao/Constituicao.htm>. Acesso em: 14. Ago. 2020.

BRASIL. Lei n. 14.010 de 10 de junho de 2020. Dispõe sobre o Regime Jurídico Emergencial e Transitório das relações jurídicas de Direito Privado (RJET) no período da pandemia do coronavírus (Covid-19). Disponível em:

http://www.planalto.gov.br/ccivil_03/_ato2019-2022/2020/lei/L14010.htm. Acesso em 18. ago. 2020.

CARDOSO, A. da S. Princípio da solidariedade: a confirmação de um novo paradigma. Revista Direito Mackenzie. v. 6, n. 1, p. 10-29, ano 2012. Disponível em: http://editorarevistas.mackenzie.br/index.php/rmd/article/view/5793. Acesso em 22. Ago. 2020.

COMPARATO, F. K. Ética: direito, moral e religião no mundo moderno. São Paulo: Companhia das Letras, 2006.

DA SILVA, J. A. Curso de Direito Constitucional Positivo. São Paulo: Malheiros Editores, 2011. 
DA SILVA, A. F. C; EFING, A. C. A Sociedade: tendências de consumo e a ética empresarial. Conpedi Law Review, Madrid - Espanha, v. 1, n. 7, p. 76-93, ano 2015. Disponível em: https://www.indexlaw.org/index.php/conpedireview/article/view/3465/2978. Acesso em 17. jul. 2020.

DECLARAÇÃO UNIVERSAL DOS DIREITOS HUMANOS. Disponível em: https://nacoesunidas.org/wp-content/uploads/2018/10/DUDH.pdf. Acesso em 22. ago. 2020.

DE LUCCA, N. Da Ética Geral à Ética Empresarial. São Paulo: Quartier Latin, 2009.

FEIL, A. A.; SCHREIBER, D. Sustentabilidade e desenvolvimento sustentável: desvendando as sobreposições e alcances de seus significados. Cadernos EBAPE.BR, v. 14, n. 3, p. 667681, Jul./Set. 2017. Disponível em: https://www.scielo.br/pdf/cebape/v15n3/1679-3951cebape-15-03-00667.pdf. Acesso em: 15. ago. 2020.

FIORILlO, C. A. P. Curso de Direito Ambiental Brasileiro. 9. ed. rev. atual. e ampl. São Paulo: Saraiva, 2008.

FROEHLICH, C. Sustentabilidade: Dimensões e métodos de mensuração e resultados. DESENVOLVE: Revista de Gestão do Unilasalle, v. 3, n. 2, set. 2014. Disponível em: https://pdfs.semanticscholar.org/d353/99be9dad178a5b18d9eb8062c0984aa0cb86.pdf. Acesso em 10. ago. 2020.

LANZARINI, C. A.; BODNAR, Z. A Sustentabilidade Empresarial como Crédito Normativo à efetividade do Instituto da Recuperação Judicial. SCIENTIA IURIS, Londrina, v. 24, n. 1, p. 124-141, mar. 2020. Disponível em:

http://www.uel.br/revistas/uel/index.php/iuris/article/view/38866. Acesso em: 15. Ago. 2020.

MACHADO, P. A. L. Direito Ambiental Brasileiro. 19. ed. rev. atual. e ampl. São Paulo: Malheiros Editores, 2011.

MAYERLE, D. A Sustentabilidade como dimensão jurídico material para recuperação judicial da empresa. 2018. 249 p. Tese (Doutorado em Ciência Jurídica) - Universidade do Vale do Itajaí - UNIVALI, Itajaí, 2018. Disponível em:

https://www.univali.br/Lists/TrabalhosDoutorado/Attachments/219/Tese\%20-

\%20Daniel\%20Mayerle.pdf. Acesso em 10. jul. 2020.

QUIVY, Raimond; CAMPENHOUDT, Luc Van. Manual de Investigação em Ciências

Sociais. Tradução. João Minhoto Marques, Maria Amália Mendes e Maria Carvalho. Lisboa: Gradiva, 2005.

SÁNCHEZ VÁZQUEZ, A. Ética. Tradução de João Dell'Anna. $31^{\mathrm{a}}$ ed. Rio de Janeiro: Civilização Brasileira, 2010.

SARRETA, C. R. L. Consumidor consciente (?): reflexões em relação às políticas públicas ambientais e importância do consumidor como ator social na globalização. I Encontro de Internacionalização do CONPEDI, v. 8. Barcelona: Ediciones Laborum, 2015. 
SEN, A; B. KLIKSBERG. As pessoas em primeiro lugar: a ética do desenvolvimento e os problemas do mundo globalizado. Tradução: Bernardo Ajzemberg, Carlos Eduardo Lins da Silva. São Paulo: Companhia das Letras, 2010.

SILVA, Marcos Alves da; SÉLLOS KNOERR, Viviane Coelho de. Responsabilidade Social da Empresa e Subcidadania Pautas para uma reflexão de índole Constitucional.

Disponível em: < http://revista.unicuritiba.edu.br/index.php/RevJur/article/view/611>. Acesso em 10 nov. 2019.

SOCIEDADE BRASILEIRA DE VAREJO E CONSUMO. Estudo novos hábitos digitais em tempos de COVID-19, 2020. Disponível em: http://sbvc.com.br/estudo-novos-habitosdigitais-em-tempos-de-covid-19/. Acesso em: 15. Ago. 2020.

SOLER, P. et. al. Modelos para evaluar la sostenibilidad de las organizaciones. Estudios Gerenciales, Cali - Colombia, v. 34, n. 146, p. 63-73, 2018. Disponível em: http://www.scielo.org.co/pdf/eg/v34n146/0123-5923-eg-34-146-00063.pdf. Acesso em 15. ago. 2020.

SOLOMON, R. C. Business Ethics. A Companion to ethics: edited by Peter Singer. Great Britain, Blackwell Publishers, 1991. Disponível em: https://dorshon.com/wpcontent/uploads/2018/03/A-Companion-to-Ethics.pdf. Acesso em: 11. jul. 2020.

SOLOMON, R. C. A Ética Empresarial. Tradução de Alexandra Abranches. Disponível em: https://criticanarede.com/fil_eticaempresarial.html. Acesso em: 04. ago. 2020.

SOUZA, M. C. de. Interesses Difusos em espécie: direito ambiental, direito do consumidor e probidade administrativa. 2. ed. rev. atual. e ampl. São Paulo: Saraiva, 2007.

TAMIOZZO, H. C.; KEMPFER, M. O pacto global e a sustentabilidade empresarial: positivação e efetividade das diretrizes e a ordem jurídica brasileira. SCIENTIA IURIS, Londrina, v. 20, n. 1, p. 144-165, abr. 2016. Disponível em:

http://www.uel.br/revistas/uel/index.php/iuris/article/view/23507. Acesso em 15. Ago. 2020. 